\title{
Moral Hazard and Earnings Manipulation
}

\author{
Anton Miglo \\ School of Business, University of Bridgeport, Bridgeport, CT 06604 \\ Corresponding Author: amiglo@bridgeport.edu
}

Copyright (C2013 Horizon Research Publishing All rights reserved.

\begin{abstract}
We consider a principal-agent relationship, where the agent is subject to a double moral hazard problem (the choice of production effort and earnings manipulation). Since the agent cannot completely capture the results of his effort, the production effort is socially inefficient. The opportunity to manipulate earnings protects the agent against the risk of a low payoff when the results of production are low. Ex-ante, this provides an incentive for the agent to improve effort. Optimal contract trades-off social loss from earnings manipulation and improved incentives for productive effort. In equilibrium some degree of earnings manipulation can be optimal.
\end{abstract}

Keywords Earnings Manipulation, Intertemporal Substitution, Incomplete Contracts, Double Moral Hazard

JEL classification codes: D86, D92, G34, J32, J33

\section{Introduction}

The corporate scandals of last decade have raised heated debates regarding the earnings manipulations by firms' insiders. Existing literature usually focuses on accounting manipulations or earnings misreporting. ${ }^{1}$ In contrast, we consider earnings manipulation (EM) to be a transfer of funds between periods. This transfer does not create any social value (in contrast to productive effort). In most cases it includes delaying the approval of important decisions, inefficient investments, borrowing in order to manipulate financial results, inefficient discount policy etc. Other examples include allowance for bad debt, cutting expenses on research and development, managing pension plans, and delay in maintenance expenditures and other important decisions (see Degeorge, Patel and Zeckhauser [3], Roychowdhury [21] and Graham et al [8]). Recent empirical papers on EM suggest that the focus of reserach should be shifted from accounting manipulation and earnings misreporting towards these kinds of actions (Graham et al [8], Huang et al [12]). In the present paper, we consider a model where EM arises as a part of the equilibrium relationships between firms' owners and managers.

We analyze a model where it is costly to verify the second-period (long-term) earnings of the firm and enforce payments contingent on it. ${ }^{2}$ This eliminates any opportunity to write a contract contingent on the firm's total value. We argue that if it is possible to write an enforceable contract contingent on the firm's total value then EM will not exists because EM does not change the firm's total value. In our model, a contract between a principal and an agent includes cash payments (bonus) and a promotion provision for the agent (the contract may contain a clause that the agent can be promoted if the first-period earnings are high enough) - both being contingent on the magnitude of the firm's short-term earnings.

We compare two situations. In the first, the agent chooses only a costly productive effort - assuming that the agent cannot be involved in EM. In the second, the agent is subject to a double-moral hazard problem which includes the choice of productive effort and the EM decision. It is shown that the parties expected payoffs can be higher in the second case. The following demonstrates the intuitions behind this result. Consider a bonus contract with promotion. If short-term earnings are below the threshold specified in the promotion condition, the agent will be fired and thus he gets nothing. Since the agent's effort is costly, the socially optimal level of effort in the first-period invloves a trade-off between the firm's expected earnings in the first period and the cost of effort. However, for the agent this trade-off is biased (compared to the socially optimal level) because of risk of being fired. In the latter case, the agent loses a large amount of earnings in the second period. As a result, he will usually provide higher than socially optimal level of effort. However, if he is able to transfer earnings between periods and

\footnotetext{
${ }^{1}$ For emipirical evidence about earnings misreporting see, among others, Dechow, Sloan and Sweeney [2] and Erickson, Hanlon and Maydew [4]. For theoretical papers see Cornelli and Yoscha [1] and Johnsen and Talley [16].

${ }^{2}$ Based on incomplete contracts literature (see, for example, Hart [10]).
} 
the firm's going concern value is relatively high, the agent can increase current earnings by reducing the firm's going concern value. This allows him to avoid layoff and make a positive profit. This in turn increases his ex-ante incentive to provide socially optimal level of effort. This argument works even if the cost of EM is relatively high.

In their well-known paper Degeorge et al [3] present a theoretical model involving EM by a manager with a bonus-like contract. The authors show that the manager's incentive to manipulate earnings depends on the values of the latent (pre-managed) earnings, the manager's bonus, and the magnitude of the social loss from EM. The manager's decision also relies on whether predictions of future profits are certain or risky. In contrast, the model in the present paper contains a double-moral hazard problem and EM arises as a part of the equilibrium relationships between firms' owners and managers.

Graham et al [8] recently found that EM via real activities manipulation is used more frequently than accounting fraud and misreporting. The management and prevention of EM becomes an important focus of an efficient corporate governance structure, firms' investors and government authorities. The position of aforementioned parties depends primarily on whether they are able to detect these manipulations and secondarily on their opinion of whether these manipulations are useful or not. With regard to the former note, Huang et al [12] argue for example that Chinese regulation has been successful because it is able to detect real manipulations. With regard to the latter note, a possible strategy is to move in the direction of a zero-tolerance policy via internal control, strict regulation and European style-corporate governance codes. For example, a manager can be fired or even charged when found conducting business in such a way. This paper points out that such a policy will not always lead to an improvement in production efficiency of corporations due to a double-moral hazard problem. The key is to understand the nature of managerial moral hazard which depends on firms' specific conditions including industrial conditions. If the firm operates in an environment with a high degree of contract incompleteness, where long-term projects and earnings are difficult to verify by third parties, some degree of earnings manipulation can be tolerable. Examples may include high-tech, internet, research, botechnology, venture firms, firms with high debt and financially distressed firms. On the other hand other industries can definitely benefit from zero-tolerance policy. Examples may include public utilities, energy producers, real estate. Our model also predicts that EM is more likely to be optimal if the cost of EM is relatively low.

Recent empirical papers provide some evidence consistent consistent with the spirit of our findings. Linck, Netter and Shu (2009) argue that EM may improve efficiency of managerial actions in financially constrained firms. Julio and Yook [17] find that intertemporal transfer of earnings can help to improve efficiency of corporate investment decisions. Jiraporn et al. [15] find that EM is more likely to occur if the cost of EM is low. Richardson, Tuna and $\mathrm{Wu}[20]$ and Hodgson and Stevenson-Clarke [11] find that firms that are involved in EM have higher debt.

The rest of this paper is organized as follows: Section 2 describes the model; Section 3 explains optimal contracting without EM; Section 4 discusses optimal contracting when the agent is subject to a double moral hazard problem which includes EM. A comparison of the outcomes is presented in Section 5 . Section 6 discusses the model's robustness and possible extensions. Section 7 discusses the model's implications with regard to empirical evidence and Section 8 presents the conclusions.

\section{Model}

Consider a firm that is owned by a Principal $(P)$. The firm's performance depends on the effort provided by a Manager $(M)$. M's effort is denoted by $e, e \in[0,1] . M$ and $P$ are risk neutral. The cost of effort is $e^{2}$. The interim first-period cash flow $r_{0}$ equals 1 with probability $e$ and 0 otherwise. The company's assets which remain at the end of first period may yield the revenue $v_{0}$ in the second period. It is assumed that $E v_{0}=2 .{ }^{3} M$ may engage in EM. If the firm is unsuccesful in the first period, $M$ may decide to shift earnings upward that will subsequently reduce the second-period earnings. Analogously, if $r_{0}=1, M$ can decide to shift earnings downward. The firm's final first-period profit is $r=r_{0}-a$, where $a$ is a profit correction arising from EM (EM takes place if $a \neq 0$ ). If $r_{0}=0, a$ can be 0 (no EM) or -1 . If $r_{0}=1, a$ can be 0 or 1 . If $a \neq 0$, the firm's earnings in the second period are thus $v=v_{0}+a-c$, where $c$ is the cost of EM, $0<c<1$. $^{4} \mathrm{EM}$ is socially inefficient $\left(a^{*}=0\right.$, where $a^{*}$ denotes the socially optimal $a$ ). To insure that earnings are non-negative in the second period we assume

$$
c \leq v_{0}-1, \forall v_{0}
$$

$M$ observes $r_{0}$ and chooses $a$. $P$ cannot observe $e$ and $a$. The first-best level of effort $e^{*}$ maximizes the firm's expected value that can be written as $E\left[r+v-e^{2}\right]=e+2-e^{2}$. Obviously, $e^{*}=1 / 2$. The reservation payoff of $M$ is $w$. We assume that the project's net present value is positive or that surplus can be created from parties' cooperation, i. e.

$$
E_{e=1 / 2, a=0}\left[r+v-e^{2}\right]=9 / 4>w
$$

\footnotetext{
${ }^{3}$ For simplicity it is assumed that the firm's second-period earnings do not depend on $e$. The model can easily be generalized by allowing this. As far as we can see, no intuitions will be affected by this change. The specific value for $E v_{0}$ is chosen arbitrarily although it assures that the going-concern value of the firm is large enough compared to current earnings.

${ }^{4}$ The cost of EM upward equals that downward. The model can be generalized by allowing different cost functions.
} 
A complete contract contingent on the second-period earnings is impossible to write. This stems from the idea that it is much more difficult to describe (ex-ante) all scenarios for long-term investments compared to short-term ones. ${ }^{5}$ Therefore, $P$ is not able to offer $M$ a complete contract contingent on the firm's total value. As we discuss in Section 5, if this were possible, the problem of EM would not exist. Thus, we assume that $P$ can only offer a complete contract contingent on first-period earnings $r$, and that $M$ has an ability to capture the firm's secondperiod earnings (similar to Hart [9]) as long as he is not fired. It is assumed that the second-period earnings of the firm are 0 in case $M$ is fired after the first period. To induce productive effort by $M, P$ offers $M$ a bonus $b$ in the case the firm is successful in the first period. In addition the contract offered by $P$ may specify the conditions under which $M$ can be fired. For simplicity we consider two following contracts. ${ }^{6}$

Bonus and promotion (denote this strategy by $s$ ). In this case, $M$ receives a bonus $b$ if $r=1$ and he is promoted regardless the size of short-term earnings. If $r=1, M$ 's overall payoff is $b+v$ and $P$ 's payoff is $1-b$. If $r=0$, $M$ 's overall payoff is $v$ and $P$ 's payoff is 0 .

Bonus and conditional promotion (denote this strategy by $f$ ). If $r=0, M$ gets nothing in the first period and he is fired afterwards. $P$ gets 0 as well. If $r=1, M$ 's is not fired and his total payoff is $b+v$ and $P$ 's total payoff is $1-b$.

The game is as follows:

1. $P$ offers contract to $M . M$ accepts or rejects the contract. If the contract is rejected, $P$ gets 0 and $M$ gets $w$.

2. $M$ chooses $e$.

3. $r_{0}$ is realized. $M$ chooses $a$.

4. $r$ and $v$ become known. The parties get their payoffs according to the contract signed.

When choosing which contract to offer, $P$ maximizes the expected value of his net earnings (payoff from the project minus the payment to $M$ ). On the one hand, the contracts should provide $M$ with the optimal incentive to choose $e$ and $a$. On the other hand, the expected value of $M$ 's payoff must cover the reservation payoff, $w$, in order for $M$ to accept the contract.

\section{Optimal Contracting without Earnings Manipulation}

Consider an optimal contract when $M$ does not manipulate earnings under any circumstance. This may be the case when the government puts in place a well developed system of corporate control which makes it highly probable that EM will be discovered. If the penalties for manipulating earnings are very high, $M$ cannot justify taking the risk. $P$ 's problem can be written as follows (problem P1).

$$
\begin{gathered}
\max _{s, f} E V_{P} \text { subject to } \\
e=\arg \max _{e} E V_{M} \\
0 \leq e \leq 1 \\
E V_{M} \geq w
\end{gathered}
$$

where $V_{M}$ and $V_{P}$ denote the payoffs of $M$ and $P$ respectively.

To solve P1 we will decompose it into two sub-problems. We first consider each type of contract separately and will summarize the results in Proposition 1. For strategy $s$, we expect that $M$ 's effort is below the first-best level of effort. This is because he bears the full cost of the effort while the results of the effort must be shared with $P$. The convexity of the effort's cost leads to a low effort in equilibrium (in the spirit of Jensen and Meckling [14]).

Lemma 1. 1) if $w \leq 33 / 16$, and $s$ is chosen, $b=1 / 2$; 2) If $w>33 / 16$ and $s$ is chosen,

$$
b=2 \sqrt{w-2}
$$

Proof. If $s$ was chosen, the $M$ 's expected payoff is $E V_{M}=E\left[b r+v_{0}-e^{2}\right]=b E(r)+v_{0}-e^{2}=b e+2-e^{2}$. Hence the optimal level of effort is

$$
e^{\prime}=b / 2
$$

This is below the first-best level of effort: $M$ gets only a fraction of the firm's profit but absorbs all the costs. $P$ 's expected payoff is

$$
E V_{P}=E[(1-b) r]=(1-b) e=b(1-b) / 2
$$

The optimal $b$ maximizes $P$ 's expected payoff, $E V_{P}$, under the condition that $E V_{M}$ is not less than $w$. From (4) we get:

$$
E V_{M}=b^{2} / 4+2
$$

\footnotetext{
${ }^{5}$ The model can be easily generalized by allowing some degree of discretion with regards to short-term earnings as well or by allowing partial verifiability of long-term earnings. The results will hold as long as the degree of entrepreneur's capacity "to steel" long-term earnings is higher than that in the short-term.

${ }^{6}$ In Section 6 we discuss more possible contracts.
} 
From (5), $P$ 's expected payoff is maximized when $b=1 / 2$. In this case $E V_{M}=33 / 16$. Thus if $w \leq 33 / 16, M$ 's budget constraint is not binding and $b=1 / 2$. If $w>33 / 16, M$ 's budget constraint is binding. Thus $b=2 \sqrt{w-2}$. End proof.

From (6), $P$ 's expected payoff is maximized when $b=1 / 2$. However, if $w$ is too large, $M$ 's participation constraint is not satisfied under $b=1 / 2$. Thus the size of bonus that must be given to $M$ becomes larger. Also note that according to (4), $M$ 's effort is less than $1 / 2$ (the first-best effort) which confirms our expectations regarding strategy $s$.

Now consider $f$.

Lemma 2. 1) If $w>2$, $f$ is not feasible; 2) if $1<w \leq 2$ and $f$ is chosen

$$
b=w-1
$$

3) if $1 \geq w$ and $f$ is chosen

$$
b=0
$$

Proof. $M$ 's choice of $e$ maximizes $E V_{M}$, where $V_{M}=b+v_{0}-e^{2}$, if $r_{0}=1$ and $V_{M}=0-e^{2}$ otherwise. Thus,

$$
E V_{M}=e(b+2)-e^{2}
$$

The maximand of this expression is $e^{\prime \prime}=\frac{2+b}{2}$. We have $e^{\prime \prime}>1$ which implies $e=1$ is optimal. $P$ 's payoff is $1-b$. Also $E V_{M}=1+b$. So for $P$ optimal $b$ is the minimal one subject to $1+b \geq w$. Thus optimal $b=w-1$. However, it must also be $b \geq 0$. Thus if $w<1$, optimal $b=0$. Also maximal possible $b=1$. Thus this contract is not feasible if $w>2$ because in this case $1+b<w$. End proof.

An explanation for Lemma 2 is as follows. Since $M$ can potentially be fired his equilibrium level of effort is higher than the first-best level of effort and respectively it costs more. So if $w$ is suffciently large, then there is no way to compensate $M$ for providing this costly effort. Otherwise $P$ choses the contract that binds $M$ 's budget constraint. If $w$ is sufficiently small, the second-period value along covers $M$ 's cost of effort and thus $P$ sets $b$ at minimal possible level.

Figure 1 illustrates intuitions behind Lemmas 1 and 2. In Figure $1 \mathrm{a} e^{\prime}<e^{*}$ and in Figure $1 \mathrm{~b} e^{\prime \prime}>e^{*}$. This follows from comparing the slopes of lines describing $M$ 's payoff with firm's value.

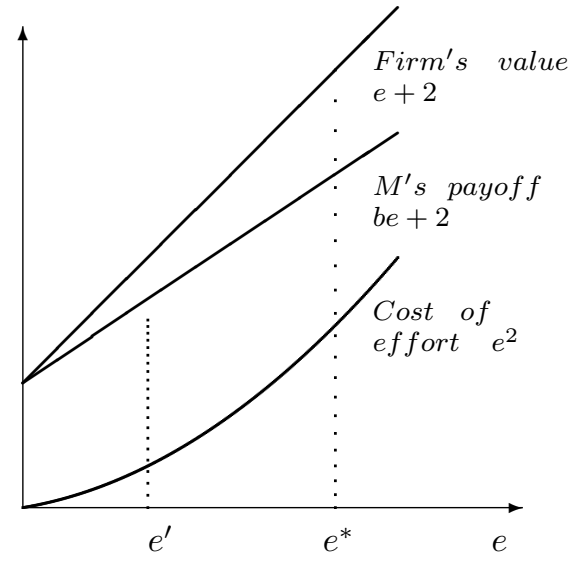

a

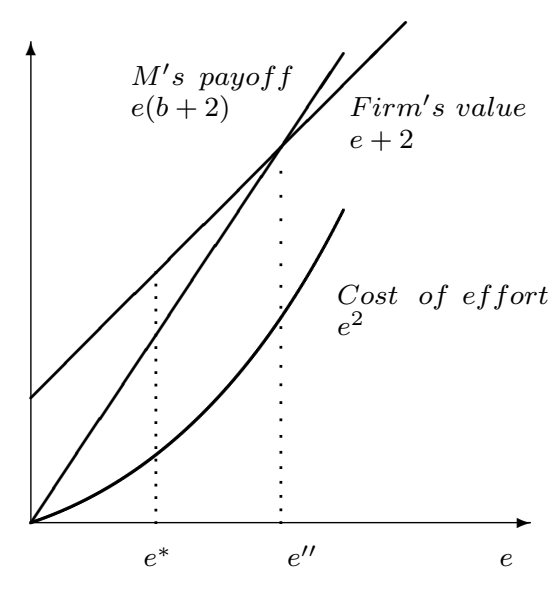

$\mathrm{b}$

Figure 1. Optimal effort under strategy: a) $s$; b) $f$.

Proposition 1. 1) If $w \leq 15 / 8, f$ is optimal; 2) If $15 / 8<w, s$ is optimal.

Proof. From Lemma 1 , if $s$ is chosen and $w \leq 33 / 16, P$ 's expected payoff is

$$
E V_{P}=\frac{1}{8}
$$

If $w>33 / 16$

$$
E V_{P}=\sqrt{w-2}(1-2 \sqrt{w-2})
$$

If $f$ is chosen and $w \leq 1$

$$
E V_{P}=1
$$

If $f$ is chosen and $1 \leq w \leq 2$

$$
E V_{P}=2-w
$$

Proposition 1 follows from comparing (10)-(13) for different values of $w$. End proof.

Under strategy $f, M$ can be fired if short-term earnings are low thus he delivers a very high effort $(e=1)$. This holds even if $b$ is quite high (as long as second-period benefits are large enough). Thus $P$ 's choice of $b$ depends 
on $M$ 's budget constraint. If $w$ is quite low, $P$ establishes a very low $b$ that maximizes his payoff as follows from (13). ${ }^{7}$ The same does not happen with strategy $s$ because the size of bonus affects $M$ 's choice of $e$ even when $w$ is low. So reducing bonus may result in lower effort. This trade-off leads to the following. As long as $M$ 's budget constraint is not binding ( $w$ is low), optimal bonus is $b=1 / 2$ which leads to $E V_{P}=1 / 8$ regardless the value of $w$. This explains why $f$ is better when $w$ is low. Finally, note that Innes [13] analyzes a similar environment (where a manager's effort is costly and EM is not allowed) with only one period (in terms of our model this means $v=0$ ) and demonstrates that "live-or-die" contract is the best one (similar to our franchise contract).

\section{Optimal Contracting with Earnings Manipulation}

Now suppose that $M$ can manipulate earnings. $P$ 's problem (P2) can be written as follows:

$$
\begin{gathered}
\max _{s, f} E V_{P} \text { subject to } \\
a=\arg \max _{a} V_{M} \\
e=\arg \max _{e} E V_{M} \\
E V_{M} \geq w \\
0 \leq e \leq 1
\end{gathered}
$$

As in the previous section, we begin by considering each contract separately. In the case of contract $s$, after observing latent earnings, $M$ may be interested in using EM by shifting earnings from the first period to the second period. The reason being a large opportunity "to steal" money from future earnings of the firm given that they are difficult to control by $P$. In addition, $M$ is not facing any risk of losing the job under strategy $s$. The trade-off for $M$ will be between capturing benefits in the second period and the value loss caused by EM. The cost of EM has a significant role to play here: if it is suffciently high, $M$ will not be engaged in EM and vice versa.

Lemma 3. 1) if $w \leq 33 / 16$ and $1 / 2 \leq c$, and $s$ is chosen, $b=1 / 2$; 2) if $w \leq 33 / 16$ and $1 / 2>c$, and $s$ is chosen, $b=1-c$; 3) If $w>33 / 16$ and $s$ is chosen,

$$
b=2 \sqrt{w-2}
$$

Proof. Consider strategy $s$. If $r_{0}=0$ and action $a$ is chosen, $M$ 's payoff is $v_{0}$, if $a=0$ and $b+v_{0}-1-c$, if $a=-1$. Since $b \leq 1, a=0$ is optimal. $M$ will not increase current earnings since he receives the firm's total second-period earnings and only a part of the firm's current earnings. If $r_{0}=1$ and action $a$ is chosen, $M$ 's payoff is $b+v_{0}$, if $a=0$ and $v_{0}+1-c$, if $a=1$. If $1-b<c, a=0$ is optimal. If $1-b>c$, the optimal $a=1$ (when the cost of EM is relatively low, $M$ will increase the firm's going concern value). (If $M$ is indifferent between $a=0$ and $a=1$, he choses $a=0$. It happens if $1-b=c$ )

If strategy $s$ is chosen, $P$ 's payoff is $(1-b) r$. If $1-b>c$, then it follows from the above paragrath that $P$ 's payoff is 0 (this cannot be an equilibrium outcome). If

$$
1-b \leq c
$$

$M$ does not manupulate earnings regardless $r_{0}$. $M$ 's expected payoff thus is $e(2+b)+(1-e) 2-e^{2}$ (i.e. with probability $e, r_{0}=1$ and $M$ gets $b r_{0}+2=2+b$ and with probability $1-e, r_{0}=0$ and $M$ gets 2$)$. $M$ 's payoff is maximized when $e=b / 2$. Analogously to Lemma $1, P$ 's expected payoff is maximized when $b=1 / 2$. Thus if $w \leq 33 / 16$ and $1 / 2<c$, optimal $b=1 / 2$ because $M$ 's participation constraint is satisfied and (15) holds. If $w \leq 33 / 16$ and $1 / 2>c$, optimal $b=1-c$. Chosing a lower $b$ leads to zero-profit for $P$ as we discussed above and chosing a higher $b$ just reduces $P$ 's payoff. If $w>33 / 16$, optimal $b$ is the minimal one which can simultaneously satisfy (15) and $M$ 's participation constraint. End proof.

As expected, the value of $c$ is important for the results of Lemma 3. If it is low, then $M$ will be engaged in EM that will sharply reduce $P$ 's final earnings. To make strategy $s$ a possible way of financing, $c$ must be sufficiently high. Note that similar to Degeorge et al [3], the choice of EM depends on the value of latent earnings and the cost of EM.

Now consider strategy $f$. Intuitively, $M$ may be interested in shifting EM upward. This can be the case if latent earnings are low. Otherwise $M$ is fired and gets nothing in the second period. We also expect that $M$ 's effort can be more efficient than in the case without EM. The opportunity to manipulate earnings protects $M$ against the risk of a low payoff when the results of production are low. This provides an incentive for $M$ to improve effort.

Lemma 4. Consider strategy $f$. 1) If $w>9 / 4-c / 2+c^{2} / 4$, $f$ is not feasible; 2) If $5 / 4-c / 2+c^{2} / 4>w$, $b=0 ; 3)$ otherwise $b=w-5 / 4+c / 2-c^{2} / 4$.

Proof. After $r_{0}$ and $v_{0}$ become known and action $a$ is chosen, $M$ 's payoff is:

$$
\begin{gathered}
0, \text { if } r_{0}=0 \text { and } a=0 \text { or } r_{0}=1 \text { and } a=1 \\
b+v_{0}, \text { if } r_{0}=1 \text { and } a=0
\end{gathered}
$$

\footnotetext{
${ }^{7}$ If $w \rightarrow 0$ then $E V_{P} \rightarrow 2$.
} 


$$
b+v_{0}-1-c, \text { if } r_{0}=0 \text { and } a=-1
$$

This means that if the firm is unsuccessful in the first period $(r=0), M$ gets nothing. Otherwise, he gets the firm's first-period residual earnings plus second-period earnings minus the cost of manipulation. Comparing (16)-(18) for given values of $c, w$ and $b$ we get the following. If $r_{0}=1, a=0$ is optimal. If latent results are good, the optimal strategy for $M$ is not to manipulate earnings. If $r_{0}=0$, the optimal $a=-1$. Therefore, $E V_{P}=1-b$. The choice of $e$ maximizes

$$
E V_{M}=e(2+b)+(1-e)(b+1-c)-e^{2}
$$

The maximand of this expression is $e^{\prime \prime \prime}=(1+c) / 2$.

Since $P$ 's expected payoff decreases in $b$, optimal $b$ is the minimal one that satisfies $M$ 's participation constraint.

$$
E V_{M}=5 / 4-c / 2+c^{2} / 4+b
$$

If $5 / 4-c / 2+c^{2} / 4>w$ then $b=0$. Otherwise $b=w-5 / 4+c / 2-c^{2} / 4$. If $5 / 4-c / 2+c^{2} / 4+1<w, f$ is not feasible. End proof.

Note that the level of effort $\left(e^{\prime \prime \prime}=(1+c) / 2\right)$ is closer to the first-best level $(e=1 / 2)$ than in the case without EM $\left(e^{\prime \prime}\right)$. This insight is illustrated in Figure 2. This is because the slope of the line describing $M$ 's expected payoff (given by equation (19)) is less than that without EM (see (9)).

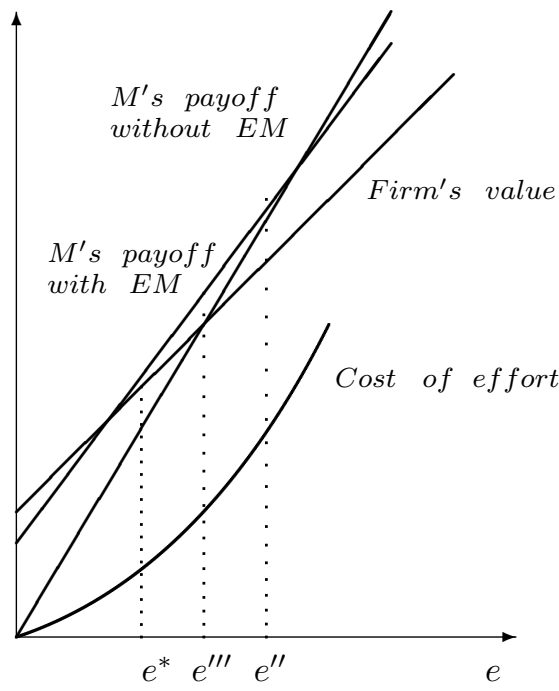

Figure 2. Optimal effort under strategy $f$ with EM.

Also, $P$ 's expected payoff is higher than in the case without EM. Again, using Lemma 2 we find that for the case $5 / 4-c / 2+c^{2} / 4<w<9 / 4-c / 2+c^{2} / 4$, it would be $2-w$. It is less than $9 / 4-c / 2+c^{2} / 4-w$.

Lemmas 3 and 4 lead to the following proposition.

Proposition 2. If $w \leq w^{*}(c), f$ is optimal, otherwise $s$ is optimal. Furthermore, $w^{*}(c)$ is decreasing in c.

Proof. See Appendix.

To illustrate the proof of Proposition 2, consider $c<2-\sqrt{10} / 2$. 1) If $w \leq 5 / 4-c / 2+c^{2} / 4$ and $s$ is chosen, $b=1-c$ and $P$ 's payoff is $c(1-c) / 2$ by $(10)$ and Lemma 3 . If $f$ is chosen, $P$ 's payoff is 1 (Lemma 4$)$. $f$ is better. 2) If $5 / 4-c / 2+c^{2} / 4 \leq w \leq 33 / 16$ and $s$ is chosen, $b=1-c$ and $P$ 's payoff is $c(1-c) / 2$ by (10) and Lemma 3 . If $f$ is chosen, $P$ 's payoff is $9 / 4-c / 2+c^{2} / 4-w$ (Lemma 4 ). $f$ is better. 3) if $33 / 16 \leq w \leq 9 / 4-c / 2+c^{2} / 4$ and $s$ is chosen, $b=2 \sqrt{w-2}$ and $P$ 's payoff is $\sqrt{w-2}(1-2 \sqrt{w-2})$. If $f$ is chosen, $b=w-5 / 4+c / 2-c^{2} / 4$ and $P$ 's payoff is $9 / 4-c / 2+c^{2} / 4-w$ (Lemma 4 ). For $w \leq w^{*}, f$ is optimal and for $w^{*} \leq w, s$ is optimal, where $w^{*}$ is the solution of $\sqrt{w-2}(1-2 \sqrt{w-2})=9 / 4-c / 2+c^{2} / 4-w$. 4) If $w \geq 9 / 4-c / 2+c^{2} / 4, d$ is not feasible and thus $s$ is optimal.

Proposition 2 is intuitive. First, if $w$ is large, $f$ is not feasible - as discussed in the case without EM. Thus, $s$ is the optimal contract. For other values of $w$, we have the following. A low $c$ is detrimental to $s$ because it creates opportunities for $M$ to engage in EM, thereby shifting the firm's value away from $P$ 's pockets. $f$ is almost always accompanied by EM, so reducing the cost of EM is beneficial for contract with promotion.

Corollary 1. Earnings manipulation can appear in equilibrium. Earnings manipulation is more probable as $c$ decreases and $w$ decreases.

Proof. From the proof of Proposition 2, if, for instance, $c<2-\sqrt{10} / 2$ and $w \leq w^{*}$, the equilibrium contract is $f$ and the firm will manipulate earnings. Also, from Proposition 2 , for a given $c$, contract with conditional promotion is optimal when $w$ is relatively low. In most cases, $f$, in contrast to $s$, will be accompanied by earnings manipulation (see the proof of Lemma 4). End proof.

It follows from Corollary 1 that managers with low outside opportunities are more likely to be involved in EM. 


\section{Can earnings manipulation enhance a firm's value?}

Now we compare firms that are involved in EM (Section 4) with those that are not (Section 3). If $w$ is high and EM is not possible, unconditional promotion is optimal. If a firm can manipulate earnings, this contract may still be optimal. However, the cost of EM must be high - otherwise the manager will "convert" current earnings into inefficient long-term projects making the unconditional promotion unfeasible (ex-ante). In the latter case, conditional promotion becomes optimal. This will usually be accompanied by EM: the manager will try to achieve the threshold to avoid a lay-off. It follows that there is a trade-off in social efficiency between the benefits from EM improving the manager's effort and the costs of EM.

Proposition 3. If $w \geq 33 / 16$, firms that manipulate earnings have on average a higher value than firms that do not.Otherwise, firms that manipulate earnings have a higher value if and only if the cost of manipulation is low.

Proof. See Appendix.

To illustrate the proof of Proposition 3 consider the case $w>33 / 16$ and $c<2-\sqrt{10} / 2$. Let $V_{E M}$ denote the value of firms that can manipulate earnings and let $V_{N}$ denote the value of firms that cannot manipulate earnings. As follows from Proposition 1, if $w>33 / 16, V_{N}=\sqrt{w-2}-2(w-2)$. According to Proposition 2 , if $w^{*}>w>33 / 16$ and $c<2-\sqrt{10} / 2, V_{E M}=9 / 4-c / 2+c^{2} / 4-w$. Hence $V_{E M}>V_{N}$. If $w>w^{*}$, $V_{N}=V_{E M}=\sqrt{w-2}-2(w-2)$.

\section{Model Discussion}

1. Suppose that it is possible to write an enforceable contract contingent on the firm's total value. Then, for any contract found in section 4 there exists an alternative contract contingent on the firm's total value that will provide $P$ with a higher payoff and that does not trigger EM. To illustrate this, suppose that $v_{0}$ can take only one value $\left(v_{0}=2\right)$ and consider $w<w^{*}(c)$. If a firm can engage in EM, the optimal contract is analogous to the one described in proposition 2. This is a contract with conditional promotion and $b=w-5 / 4+c / 2$. E's effort is $e=(1+c) / 2$ and the parties expected payoffs are:

$$
E V_{P}=9 / 4-w-c / 2+c^{2} / 4
$$

and $E V_{E}=w$. When $r_{0}=0, M$ receives $b+1-c$ and when $r_{0}=1$ he receives $b+2$. Now suppose the parties write a contract where $M$ gets $b+1-c$ if the firm's total value is 2 or less and $b+2$ if the firm's total value is greater than 2. The optimal effort maximizes E's expected payoff $e(b+2)+(1-e)(b+1-c)-e^{2} \cdot e=(1+c) / 2$ is optimal. Also, $a=0$ because any $a>0$ will only reduce the firm's total value. E's expected payoff is $9 / 4-w$ which is greater than (21). $P$ 's expected payoff is $9 / 4-w$. Therefore, we have a better contract which does not involve EM.

Note that suggested contract is non-linear in the firm's value. In Liang [18] the firm can only issue linear contracts. Then one can show that such a contract is not nesseraliy better than a contract with EM. Indeed suppose that second-period earnings are verifiable but the firm can only offer a linear contract on the firm total value. Denote this as $(1-h)(r+v)$, where $h$ id the fraction of total earnings belonging to $P$. Then $M$ 's payoff is $(1-h)(e+v)-e^{2}$. Optimal $e=(1-h) / 2$. P's payoff is $h(1-h) / 2+2 h$. M's payoff is $(1-h)^{2} / 2+2(1-h)-(1-h)^{2} / 4$. Since $P$ 's expected payoff increases in $h$, optimal $h$ is the maximal one that satisfies $M$ 's participation constraint. We have: $(1-h)^{2} / 4+2(1-h)=w$. Thus $w=2-\sqrt{1+4 w}$. For example, if $w=0, h=1$ and $E V_{P}=2$ that is less that his payoff with EM determined by (21). It would be $9 / 4$.

2. One can make additional assumptions about the first and second period sharing rules based on a continuous earnings distribution function or different control shifting scenarios. These scenarios may yield some new results. For instance, one can assume that $M$ can capture only a fraction of firm's going concern value. In this case, the set of possible contracts can be significantly larger than in the basic set-up. However, the main idea that EM can improve productive effort will not be affected given that one keeps the assumption about contract incompletness.

\section{Empirical evidence and policy implications.}

1. We have shown that EM can be a part of the equilibrium relationship between firms' owners and managers. This holds even if the cost of EM is relatively high (as follows from Proposition 2). Principal (shareholders) accept some degree of EM because this increases the managers' incentive to provide a high level productive effort.

2. From Proposition 3, if the cost of EM is relatively low, EM can be socially efficient. EM can enhance a firm's value when compared to the case without EM. If the cost of EM is relatively high, the opportunity to engage in EM either does not affect firms' values (when they do not use EM in equilibrium) or is detrimental to firms' values (when firms engage in EM in equilibrium). Some recent evidence in the study by Jiraporn et al [15] is consistent with this prediction although they are not specifically focused on real earnings manipulations. So additional research is required here.

3. EM should more frequently be observed in industries characterized by incomplete contracts. If complete contracts can be written, the parties can write a contract contingent on the firm's overall earnings which eliminates 
the possibility of EM. Thus, firms in industries which are characterized by a high degree of technological or market uncertainty (such as software, internet, biomedical etc.) are more likely to be engaged in EM. In similar spirit Francis et al [7] find that EM is inconsistent with efficient contracting.

4. As implied by Corollary 1, EM should more frequently be observed among managers with low outside opportunites (low $w$ ).

5. Firms which manipulate earnings issue contracts with conditional promotion (Lemmas 3 and 4 ). This is consistent with recent reserach which links EM and management career concerns (see, for example, Farrel and Whidbee [5] and Feng et al [6]).

Since EM can be socially efficient, the question of its regulation depends on the industry and any parameters related to the firm's projects. If the cost of EM is relatively low, putting in place an expensive public system of EM prevention cannot be efficient: entrepreneurs will invest less funds in socially efficient projects and will not provide high levels of productive effort. According to our analysis (proof of Proposition 3), such a system should target average-profit firms (when the cost of EM is relatively high) or high-profit firms (when the cost of EM is in the intermediate range).

\section{Conclusion}

The corporate scandals of last decade have raised heated debates regarding EM by firms' insiders. Graham et al [8] recently found that EM is used more frequently than accounting fraud and misreporting. Existing literature usually considers EM to be a negative social phenomenon and suggests measures for its elimination. In the present paper, we argue that zero tolerance policy towards EM may be socially inefficient. We analyze a model where a manager's productive effort is not observable by the firm's owner. The optimal contract should provide the manager with the optimal incentive to provide productive effort. The equilibrium level of effort is not socially optimal. Following this, we analyze the case where in addition to productive effort the manager can be engaged in EM that reduces the firm's total value. EM consists of transferring cash flow between periods. Our main finding is that the existence of EM can lead to increased output and therefore, improved social efficiency. It is shown that EM should be observed more often among firms with low profitability, low costs of EM, and where managers have low outside opportunities. A public system of EM prevention should target average-profit firms (when the cost of EM is relatively high) or high-profit firms (when the cost of EM is in the intermediate range).

\section{Appendix}

Proof of Proposition 2. Consider $c<2-\sqrt{10} / 2$. 1) If $w \leq 5 / 4-c / 2+c^{2} / 4$ and $s$ is chosen, $b=1-c$ and $P$ 's payoff is $c(1-c) / 2$ by (10) and Lemma 3 . If $f$ is chosen, $P$ 's payoff is 1 (Lemma 4 ). $f$ is better. 2 ) If $5 / 4-c / 2+c^{2} / 4 \leq w \leq 33 / 16$ and $s$ is chosen, $b=1-c$ and $P$ 's payoff is $c(1-c) / 2$ by (10) and Lemma 3 . If $f$ is chosen, $P$ 's payoff is $9 / 4-c / 2+c^{2} / 4-w$ (Lemma 4). $f$ is better. 3) if $33 / 16 \leq w \leq 9 / 4-c / 2+c^{2} / 4$ and $s$ is chosen, $b=2 \sqrt{w-2}$ and $P$ 's payoff is $\sqrt{w-2}(1-2 \sqrt{w-2})$. If $f$ is chosen, $b=w-5 / 4+c / 2-c^{2} / 4$ and $P$ 's payoff is $9 / 4-c / 2+c^{2} / 4-w$ (Lemma 4 ). For $w \leq w^{*}, f$ is optimal and for $w^{*} \leq w, s$ is optimal, where $w^{*}$ is the solution of $\sqrt{w-2}(1-2 \sqrt{w-2})=9 / 4-c / 2+c^{2} / 4-w$. 4) If $w \geq 9 / 4-c / 2+c^{2} / 4, f$ is not feasible and thus $s$ is optimal.

Consider $1 / 2>c>2-\sqrt{10} / 2$. 1) If $w \leq 5 / 4-c / 2+c^{2} / 4$ and $s$ is chosen, $b=1-c$ and $P$ 's payoff is $c(1-c) / 2$ by (10) and Lemma 3. If $f$ is chosen, $P$ 's payoff is 1 (Lemma 4). $f$ is better. 2) If $5 / 4-c / 2+c^{2} / 4 \leq w \leq 9 / 4-c / 2+c^{2} / 4$ and $s$ is chosen, $b=1-c$ and $P$ 's payoff is $c(1-c) / 2$ by $(10)$ and Lemma 3 . If $f$ is chosen, $b=w-5 / 4+c / 2-c^{2} / 4$ and $P$ 's payoff is $9 / 4-c / 2+c^{2} / 4-w$ (Lemma 4). Thus $f$ is better if and only if $w \leq w^{*}(c)=9 / 4-c+3 / 4 c^{2}$. 3) if $9 / 4-c / 2+c^{2} / 4 \leq w, f$ is not feasible.

Consider $1 / 2<c$. 1) If $w \leq 5 / 4-c / 2+c^{2} / 4$ and $s$ is chosen, $b=1 / 2$ and $P$ 's payoff is $1 / 8$ by (10) and Lemma 3. If $f$ is chosen, $P$ 's payoff is 1 (Lemma 4 ). $f$ is better. 2) If $5 / 4-c / 2+c^{2} / 4 \leq w \leq 9 / 4-c / 2+c^{2} / 4$ and $s$ is chosen, $b=1 / 2$ and $P$ 's payoff is $1 / 8$ by (10) and Lemma 3 . If $f$ is chosen, $b=w-5 / 4+c / 2-c^{2} / 4$ and $P^{\prime}$ 's payoff is $9 / 4-c / 2+c^{2} / 4-w$ (Lemma 4$)$. $f$ is better if and only if $w \leq w^{*}(c)=17 / 8-c / 2+c^{2} / 4$. 3) if $9 / 4-c / 2+c^{2} / 4 \leq w, f$ is not feasible.

Also note that $w^{*} \geq 33 / 16$ for the case $c<2-\sqrt{10} / 2$ and $w^{*} \leq 33 / 16$ for the case $1 / 2>c>2-\sqrt{10} / 2$. Also the solution of $\sqrt{w-2}(1-2 \sqrt{w-2})=9 / 4-c / 2+c^{2} / 4-w$ decreases in $c$. To see this let us rewrite this equation as $\sqrt{w-2}-w+7 / 4=-c / 2+c^{2} / 4$. The right side decreases in $c$ and the left side increase in $w$. Also expressions $9 / 4-c+3 / 4 c^{2}$ and $17 / 8-c / 2+c^{2} / 4$ decrease in $c$ in corresponding regions. End proof.

Proof of Proposition 3. Let $V_{E M}$ denote the value of firms that can manipulate earnings and let $V_{N}$ denote the value of firms that cannot manipulate earnings. As follows from Proposition 1 , if $w>33 / 16, V_{N}=\sqrt{w-2}-$ $2(w-2)$. According to Proposition 2, if $w^{*}>w>33 / 16$ and $c<2-\sqrt{10} / 2, V_{E M}=9 / 4-c / 2+c^{2} / 4-w$. Hence $V_{E M}>V_{N}$. If $w>w^{*}, V_{N}=V_{E M}=\sqrt{w-2}-2(w-2)$. Consider $c>2-\sqrt{10} / 2$. From Proposition 2, $V_{N}=V_{E M}=\sqrt{w-2}-2(w-2)$.

Consider $15 / 8<w<33 / 16$. From Proposition $1, V_{N}=1 / 8$. According to Proposition 2 , if $15 / 8<w<w^{*}$ (note that $\left.5 / 4-c / 2+c^{2} / 4<15 / 8\right)$ and $c<2-\sqrt{10} / 2, V_{E M}=9 / 4-c / 2+c^{2} / 4-w$. Thus if $c<(2-\sqrt{3}) / 2$, 
$V_{E M}>V_{N}$. Otherwise $V_{E M}<V_{N}$. Consider $1 / 2>c>2-\sqrt{10} / 2$. From Proposition $2, V_{E M}=c(1-c) / 2$. Thus $V_{E M}<V_{N}$. If $c>1 / 2, V_{N}=V_{E M}=1 / 8$. If $w^{*}<w<33 / 16$ (note that $5 / 4-c / 2+c^{2} / 4<15 / 8$ ) and $c<2-\sqrt{10} / 2, V_{E M}=c(1-c) / 2$. Thus $V_{E M}<V_{N}$. Consider $1 / 2>c>2-\sqrt{10} / 2$. From Proposition 2 , $V_{E M}=c(1-c) / 2$. Thus $V_{E M}<V_{N}$. If $c>1 / 2, V_{N}=V_{E M}=1 / 8$.

Consider $15 / 8>w>1$. From Proposition $1, V_{N}=2-w$. According to Proposition 2, if $15 / 8>w>1$ and $c<2-\sqrt{10} / 2, V_{E M}=9 / 4-c / 2+c^{2} / 4-w$. Thus $V_{E M}>V_{N}$. Consider $c>2-\sqrt{10} / 2$. If $5 / 4-c / 2+c^{2} / 4 \leq w$, $V_{E M}=9 / 4-c / 2+c^{2} / 4-w$. Thus $V_{E M}>V_{N}$. If $5 / 4-c / 2+c^{2} / 4>w, V_{E M}=1$. Thus $V_{E M}>V_{N}$.

Consider $w<1$. From Proposition $1, V_{N}=1$. According to Proposition 2, $V_{E M}=1$. Thus $V_{E M}=V_{N}$. End proof.

\section{Acknowledgements}

I would like to thank Hikmet Gunet, Pierre Lasserre, Pierre Liang, Nicolas Marceau, Michel Robe, and the seminar and conference participants at UQAM, University of Canterbury and EEA 2010 annual meeting for their comments. Many thanks to Bennett Minchella for editing assistance.

\section{REFERENCES}

[1] Cornelli, F. and O. Yosha. 2003. Stage Financing and the Role of Convertible Securities, Review of Economic Studies Vol. 70, 1-32.

[2] Dechow, P., Sloan, R., and A. Sweeney. 1996. Causes and Consequences of Earnings Manipulation: An Analysis of Firms Subject to Enforcement Actions by SEC, Contemporary Accounting Research, 13, 1-36.

[3] Degeorge, F., Patel, J. and R. Zeckhauser. 1999. Earnings Management to Exceed Thresholds. The Journal of Business Vol. 72, No. 1, 1-33.

[4] Erickson M., M. Hanlon and E. Maydew. 2003. Is There a Link Between Executive Compensation and Accounting Fraud? Working paper, University of Michigan

[5] Farrell, K. A. and D. Whidbee, 2003. The Impact of Firm Performance Expectations on CEO Turnover and Replacement Decisions. JAE Boston Conference October 2002. Available at SSRN: http://ssrn.com/abstract=318968.

[6] Feng, M., Ge, W., Luo, S. and T. Shevlin, 2010. Why do CFOs Become Involved in Material Accounting Manipulations?. AAA 2009 Financial Accounting and Reporting Section (FARS) Paper. Available at SSRN: http://ssrn.com/abstract $=1260368$.

[7] Francis, J., Huang, A., Rajgopal, S. and Amy Zang. 2004. CEO Reputation and Earnings Quality. Working paper, available at SSRN: http://ssrn.com/abstract=609401 or doi:10.2139/ssrn.609401.

[8] Graham, J., C. Harvey, and S. Rajgopal. 2005. The Economic Implications of Corporate Financial Reporting. Journal of Accounting and Economics Vol. 40, 3-73.

[9] Hart, O. 1988. Incomplete Contracts and the Theory of the Firm. Journal of Law, Economics and Organization Vol. 4, No 1, 119-39.

[10] Hart, O. 1995. Firms, Contracts and Financial Structure. Oxford University Press.

[11] Hodgson, A., and P. Stevenson-Clarke, 2000, Accounting Variables and Stock Returns: The Impact of Leverage, Pacific Accounting Review, Vol. 12, No. 2, 37 - 64 .

[12] Huang, T., A. Szczesny, A., and A. Lenk. 2008. Substitution, Availability and Preferences in Earnings Management: Empirical Evidence from China. Review of Managerial Science Vol. 2, 129-160.

[13] Innes, R., 1990. Limited Liability and Incentive Contracting with ex-ante Choices, Journal of Economic Theory Vol. $52,45-67$.

[14] Jensen, M., and W. Meckling. 1976. Theory of the Firm: Managerial Behavior, Agency Costs and Ownership Structure, Journal of Financial Economics Vol. 3, No. 4, 305 - 360.

[15] Jiraporn, P., G. Miller, S. Yoon, and Y. Kim. 2008. Is Earnings Management Opportunistic or Beneficial: An Agency Theory Perspective. working paper.

[16] Johnsen, G., and E. Talley. 2005. Corporate Governance, Executive Compensation and Securities Litigation. SSRN Working paper.

[17] Julio, B. and Y. Yook. 2009. Earnings Management and Corporate Investment Decisions, London Business School, working paper 
[18] Liang, P. 2004. Equilibrium Earnings Management, Incentive Contracts, and Accounting Standards. Contemporary Accounting Research 21 (3): 685 - 718.

[19] Linck, J. S., Netter, J. M. and T. Shu. 2009. Can Earnings Management Ease Financial Constraints ${ }^{6}$ Evidence from $^{-}$ Earnings Management Prior to Investment. Working paper, available at SSRN: http://ssrn.com/abstract=1535990

[20] Richardson, S., I. Tuna and M. Wu, 2002, Predicting Earnings Management: The case of earnings restatements, Working Paper, University of Pennsylvania.

[21] Roychowdhury, S. 2005. Earnings Management through Real Activities Manipulation. Journal of Accounting and Economics Vol. 42, No. 3, 335-370. 